\title{
Em primeira pessoa
}

\section{In first person}

\author{
Alfredo Naffah Neto ${ }^{1}$ \\ Professor Titular da Pontifícia Universidade Católica de São Paulo \\ E-mail:naffahneto@gmail.com
}

Resumo: O presente artigo parte de um texto publicado por Zeliko Loparic para discutir o processo de regressão à dependência, em pacientes de tipo borderline na clínica psicanalítica winnicottiana. Recupera, para tanto, o sentido etimológico da termo sujeito, para descrever, então, o que poderia ser entendido como alienação do sujeito (devidos a falhas ambientais) e a sua retomada em primeira pessoa, nos processos de regressão à dependência. $\mathrm{O}$ artigo se completa tecendo considerações sobre a temporalidade humana saudável e a sua versão patológica, quando partes da personalidade são congeladas no tempo.

Palavras-chave: Palavras-chaves: sujeito, alienação do sujeito, temporalidade, amadurecimento.

Abstract: This article takes into account a published text written by Zeliko Loparic in order to discuss the process of regression to dependence in borderline patients, in Winnicott's clinical psychoanalysis. For this purpose, it recovers the etymological meaning of the word subject, in order to describe what could be understood as subject alienation (caused by environmental failures) and the recovering of the subject in the first person, by means of the processes of regression to dependence. The article finishes making considerations about healthy human temporality and its pathological version, when parts of the personality are frozen in time.

\footnotetext{
${ }^{1}$ É psicanalista, mestre em filosofia pela USP, doutor em psicologia clínica pela PUC-SP, onde leciona como professor titular no Programa de Estudos Pós-Graduados em Psicologia Clínica. Além disso, pratica psicanálise, psicoterapia de casal (e de família) em consultório particular. É, também, professor colaborador e supervisor da Sociedade Brasileira de Psicanálise Winnicottiana e da International Winnicott Association (IWA), tendo recentemente colaborado na formação de psicanalistas na China. Suas pesquisas atuais versam sobre convergências e divergências teórico-clínicas entre diferentes escolas psicanalíticas, incluindo autores como: Freud, Ferenczi, Klein, Bion, Winnicott, Lacan, Green, Roussillon etc. Também realiza pesquisas sobre relações entre psicanálise e música (ópera e música popular, principalmente). Vem publicando artigos e livros sobre esses temas.
} 
Keywords: subject, subject alienation, temporality, maturation.

\section{Considerações iniciais}

O maior valor de um artigo científico ou filosófico não está nas respostas dadas, mas nas perguntas que suscita e que nos fazem refletir. Pois respostas são sempre limitadas por questões de tempo e espaço, enquanto perguntas multiplicam-se na passagem de um leitor para outro.

Também acontece que, quanto mais nos aprofundamos no estudo de um autor, menor - em geral - é o grau de surpresa quando lemos artigos que falam sobre ele, esmiuçando e detalhando partes do seu pensamento, pois é frequente que a maior parte dessas ideias já nos tenham passado pela cabeça e tomado forma em algum lugar. É, pois, de grande importância quando somos pinçados por algo inusitado, que nos surpreende por parecer, ao mesmo tempo, novo e velho, surpreendente e óbvio; talvez por nunca ter sido formulado com tanta clareza. Essa foi a minha sensação ao ler algumas partes do artigo de Zeliko Loparic sobre Winnicott, intitulado "Temporalidade e regressão" e publicado na revista Winnicott e-Prints (Loparic, 2014). Gostaria, assim, de desenvolver as reflexões que essas passagens me suscitaram. É uma forma de valorizar suas descobertas, bem como de ressoá-las em mim, produzindo desdobramentos.

Não pretendo realizar uma análise completa do referido artigo, parágrafo por parágrafo, pois isso fugiria completamente aos meus propósitos aqui. Trata-se, tão somente, de pinçar alguns trechos do seu discurso; aqueles que me mobilizaram e puseram-me a refletir, ou seja, aqueles que produziram um impacto novo e reverberante. A partir deles, pretendo desenvolver as minhas próprias reflexões ${ }^{2}$.

\section{As regressões à dependência e a retomada do amadurecimento em primeira pessoa}

Começo, pois, citando um trecho em que Loparic descreve o funcionamento das regressões à dependência nos processos psicanalíticos, tendo em vista, principalmente, pacientes difíceis, de tipo borderline, devido à necessidade que têm desse tipo de

\footnotetext{
${ }^{2}$ Ao leitor interessado no artigo completo, recomendo vivamente a sua leitura.
} 
regressão terapêutica para retomarem o seu processo de amadurecimento que ficou congelado no tempo devido a falhas ambientais graves ${ }^{3}$. Loparic nos diz:

O setting apropriado para o atendimento das regressões à dependência não visa a recolocar na boa ordem temporal e causal os conteúdos vividos no passado e expulsos do sistema Cns., mas, pelo contrário, permitir (não induzir) que o que não foi vivido no passado seja vivido pela primeira vez no presente, no agora. Não se trata de propiciar dessa maneira satisfações compensatórias corretivas (1965, p. 258; tr. p. 233), mas de oferecer ao paciente mediante participação no seu modo de ser a oportunidade de retomar, em primeira pessoa, o processo de amadurecimento (Loparic, 2014, p. 16).

As três palavras mágicas do texto, para mim, foram: em primeira pessoa, ou seja, as regressões servem justamente para que o paciente retome, em primeira pessoa, o seu processo de amadurecimento congelado, participando ativamente da construção do seu destino. Não se trata, para Winnicott, de corrigir ou remendar o passado traumático, mas de criar uma oportunidade de participação do seu principal agente, que ficou alienado da construção de sua história de vida por ocasião de falhas ambientais. Entretanto, convém explicitar melhor essa questão, que é o que tentarei fazer a seguir.

Primeiramente, é importante considerar que, para que o desenvolvimento do bebê - tal qual concebido por Winnicott - venha a ocorrer de forma saudável, este necessita ser realizado sempre em primeira pessoa. Por essa razão, essas três palavras produziram em mim um efeito quase mágico, como se descrevessem, de forma econômica e sucinta, tudo que precisa acontecer para que haja saúde psíquica. Em outras palavras, é preciso que o bebê seja sempre o sujeito do seu destino, no sentido etimológico do termo latino subjectus: posto debaixo; colocado, situado debaixo (Torrinha, s/d, p. 829). Assim, sujeito é aquele que subjaz, que está subentendido na produção de uma história de vida ${ }^{4}$.

\footnotetext{
${ }^{3}$ Em primeiro lugar, convém entender o termo borderline, aqui utilizado num sentido amplo, descrevendo aquelas patologias fronteiriças, situadas entre a neurose e a psicose (portanto, compreendendo tanto os esquizoides quanto os de "personalidade como se", descritos por mim em artigos anteriores [Naffah Neto, 2007/2017; Naffah Neto, 2010/2017]). Em segundo lugar, saliento que, além dos pacientes de tipo borderline, aqueles que exibem tendências antissociais e algumas modalidades de neuróticos também podem necessitar desse tipo de regressão, os últimos especialmente quando revelam núcleos psicóticos ao longo da análise.

${ }^{4}$ Não cabe aqui qualquer referência, explícita ou velada, a Lacan e à sua proposta de um sujeito do inconsciente, o qual fala nas lacunas do discurso consciente sob a forma de atos falhos, chistes etc. Tratase, sim, de algo inteiramente diferente, de um sujeito capaz de criar um mundo e uma vida concebidos à sua medida, muito embora se trate, também, de um sujeito inconsciente. Mas ele o é em um sentido totalmente diferente do lacaniano, já que não estamos mais falando do inconsciente recalcado, mas de processos primitivos que acontecem em uma época em que a consciência ainda não se encontra sequer constituída e, portanto, de processos que não poderiam de forma alguma se tornar conscientes.
}

Revista Natureza Humana, São Paulo, v.21, n.2, pp.211-219, 2019. 
Entretanto, também é verdade que, nos primeiros tempos, o bebê só pode se tornar sujeito do seu destino a partir de uma ilusão. Isso porque, ao longo de todo o processo de dependência, o seu amadurecimento somente se realiza às custas de um ambiente suficientemente bom, quer dizer, capaz de sustentá-lo tanto física quanto psiquicamente. É somente assim que o pequeno rebento pode ir elaborando imaginativamente as suas funções corporais e criando, paulatinamente, a sua psique nelas ancorada, de forma a constituir, mais adiante, uma unidade psicossomática. Entretanto, é preciso que o bebê seja iludido, sentindo-se onipotente e senhor do seu destino desde o início. Assim, o bebê cria o seio materno por ele encontrado, paradoxo no qual o bebê o constitui à medida das suas necessidades, sustentado por uma mãe suficientemente boa, que ele ignora completamente, já que com ela se confunde e se identifica (identificação primária, segundo Winnicott). Nessa ilusão de onipotência, o bebê é o sujeito de sua história de vida.

Entretanto, esse sujeito ainda não existe inteiramente constituído, isto é, podemos dizer que não existe nenhuma pessoa ou que existe exclusivamente a primeira pessoa (considerando a experiência do bebê). Isso se torna menos complexo se lembrarmos que, nos tempos primitivos, o bebê funde-se com o ambiente nos estados de relaxamento, entrando em uma espécie de vivência oceânica - portanto, em sua experiência, não existe nenhuma pessoa. Entretanto, nos períodos em que é atravessado por uma urgência instintual e sofre integrações espaciotemporais efêmeras (capazes de conduzi-lo à busca do seio), um sujeito evanescente emerge para desaparecer em seguida - portanto, nesses fragmentos de tempo, existe somente a primeira pessoa.

O mesmo fenômeno se repete na criação do objeto transicional - fralda, ursinho etc. -, embora, nesse período, a existência da segunda pessoa comece a se revelar pouco a pouco. Por conta disso, Winnicott designa esse tipo de objeto como uma posse não-eu (Winnicott, 1971/1991, p. 4), ou seja, nele já está presente, de alguma forma, o não-eu.

Com a criação do mundo externo, na fase do uso do objeto (Winnicott, 1968/1991), a segunda pessoa faz, enfim, a sua aparição mais completa, finalmente desiludindo o bebê de sua onipotência criadora: a descoberta de que o mundo que criou já existia antes dele. Ocorre, então, a distinção entre fantasia e realidade, o que torna possível o recalque das fantasias intoleráveis, tendo início o inconsciente recalcado. 
No estágio do concernimento ${ }^{5}$, a criança já visará o outro como um semelhante, cujo corpo destrói em sua fantasia (sadismo oral), gerando culpa e desejos reparatórios (Winnicott, 1960a/1990). Aqui já existe um sujeito constituído - um eu razoavelmente senhor de suas ações -, mas esse sujeito já se espraia em uma intersubjetividade (eu e tu: primeira e segunda pessoas). Graças à sustentação dos atos reparatórios do bebê pela mãe suficientemente boa, ele pode ir incorporando ao self - com menos culpa - os impulsos agressivo-destrutivos que o atravessam de quando em quando e pode, enfim, fundi-los aos impulsos eróticos em uma sexualidade infantil razoavelmente constituída. Nesse estágio, constitui-se uma ética da relação com o outro que, se tudo correr bem, passará a ser respeitado como um semelhante.

O complexo de Édipo fará, enfim, aparecer a terceira pessoa na figura do pai e, com ela, a quarta, a quinta e toda a sociedade na qual a criança está inserida e que se fará presente através da escola, dos amigos, dos parentes.

A primeira pessoa continua à frente da sua história, mas conhecendo as limitações impostas pela sociedade e pela cultura. A essa altura, a criança já formou um falso self saudável, isto é, já consegue pagar o seu tributo à necessária vida em sociedade sem perder contato com o seu mundo subjetivo - sua espontaneidade e criatividade.

Mas o que acontece quando falhas ambientais precoces produzem um congelamento do processo de amadurecimento do bebê através da criação de um falso self patológico que, por meio do mecanismo da cisão, passa a encobrir o self verdadeiro, ainda em estado embrionário, como uma espécie de escudo protetor? Ocorre o que poderíamos designar como uma alienação da primeira pessoa na alteridade, ou seja, na segunda pessoa. Assim, o bebê deixa de agir em primeira pessoa - a partir de suas necessidades próprias - para reagir às intrusões de um ambiente traumatogênico, mimetizando seus traços na formação desse falso self patológico (Winnicott, 1960b/1990, p. 146-7). Com o encobrimento do self verdadeiro, a primeira pessoa se eclipsa e quem assume o seu lugar é um mimetismo de outrem.

Por essa razão, nas regressões à dependência, trata-se, justamente, de restaurar o funcionamento em primeira pessoa, propiciando ao paciente a participação ativa na construção do seu destino.

\footnotetext{
${ }^{5} \mathrm{Na}$ verdade, a palavra de língua portuguesa correta para traduzirmos o inglês concern é "concernência", mas mantenho, aqui, o neologismo "concernimento" proposto por Elsa Oliveira Dias.
} 


\section{Temporalidade e expansão do self na saúde psicossomática}

Um outro fragmento do artigo do Zeliko que me mobilizou - e o qual gostaria de comentar - trata da noção de temporalidade proposta por Winnicott, necessária para que possamos entender o processo de regressão à dependência. Eu o cito:

A fim de entender essa concepção de temporalidade da regressão $[\ldots]^{6}$ convém observar que, segundo Winnicott, "as pessoas não têm exatamente sua idade; em alguma medida, elas têm todas as idades ou nenhuma" (1986, p. 81, tr. p. 64; os itálicos são meus). Na saúde, o ser aí humano estende-se por todos os estágios, o tempo todo, isto é, ele transcende cada um deles e ocupa todo o tempo do existir, tanto o passado quanto o futuro. Ele nunca existe apenas em uma das dimensões do tempo, mas sempre em todas. Mais ainda, ele transcende a integração no tempo, como tal, razão pela qual, mesmo sem eterno, ele não tem idade alguma (Loparic, 2014, p. 13).

Assim, há sempre uma loucura do bebê no adulto sadio. Quando falamos do amadurecimento infantil, sadio, "sabemos que estamos falando da infância toda, em particular da adolescência; e, se estivermos falando da adolescência, estaremos falando de adultos, pois nenhum adulto é adulto o tempo todo (1986, p. 81 ; tr. p. 64). O primado do passado, a redução do existir a uma sequência dos agora ou a perda da abertura para o futuro são sinais de patologias. A estrutura da personalidade do indivíduo winnicottiano que amadurece de modo sadio inclui a relação com o passado, o presente e o futuro, portanto, isto é, com o todo do tempo (Loparic, 2014, p. 13).

Talvez esta constitua uma das mais belas descrições da temporalidade humana saudável que já li num texto acadêmico; por isso a decisão de deixá-la ecoar em meu pensamento.

Porém, antes de comentar a temporalidade saudável, convém retomar brevemente a problemática da temporalidade patológica: o tempo congelado, característico do paciente borderline. Eu não acredito, a partir de minha experiência clínica, que esse congelamento seja absoluto, ou seja, que o todo da personalidade borderline fique congelado no tempo, à espera de melhores condições ambientais para um degelo e, consequente, para a retomada do processo de amadurecimento.

O que a clínica tem me mostrado é que esse tipo de paciente atravessa todas as etapas do amadurecimento, mas o faz aos trambolhões, de forma incompleta e, muitas vezes, sem conseguir integrar no self a maior parte das experiências que pressupunham o

\footnotetext{
${ }^{6} \mathrm{O}$ fragmento elidido aqui é "[...] - que, como é fácil de notar, contraria a tese de Freud de atemporalidade do inconsciente - [...]" (Loparic, 2014, p. 13). Eu o suprimi propositalmente, pois entendo que para discutir essa questão complexa - da temporalidade ou atemporalidade do inconsciente -, necessitaria escrever um outro artigo. Portanto, por questões de tempo e espaço, deixo essa discussão para outras empreitadas.
}

Revista Natureza Humana, São Paulo, v.21, n.2, pp.211-219, 2019. 
atravessamento das etapas anteriores. À guisa de exemplo, cito o caso de Margaret Little, analisada por Winnicott. Eis aqui um episódio da referida análise, narrado por ela, quando ainda se encontrava lutando para sair da psicose:

Eventualmente, ele [Winnicott] contou-me do seu divórcio e recasamento que se aproximava, ou bem eu devo ter ouvido isso em algum lugar ou lido na imprensa. Eu achei difícil, especialmente porque o meu caso amoroso estava finalmente se rompendo. Fiquei ciumenta e algum material edipiano pôde ser trabalhado, muito embora tenha permanecido como um remendo isolado, que necessitou ser reunido mais tarde (Little, 1990, p. 55, a tradução e os itálicos são meus).

Essa descrição ilustra brevemente o que tentei descrever antes, atestando que partes da personalidade de Little atravessaram incipientemente a problemática edipiana enquanto outras permaneciam congeladas em estágios primitivos. Entretanto, por conta da falta das conquistas necessárias nas etapas intermediárias (especialmente da capacidade de suportar ambivalência, alcançada no estágio do concernimento), o material edipiano não pôde ser absorvido pelo self de Little, permanecendo marginal à sua psique e tendo de ser integrado posteriormente, como um remendo. Isso foi feito, evidentemente, em sua segunda análise com Winnicott, quando - ultrapassada a condição borderline elaboravam-se, justamente, questões edipianas.

Decorre justamente dessa precariedade do desenvolvimento do paciente borderline - que deixou pedaços importantes para trás, congelados no tempo - a necessidade das regressões à dependência as quais, ao oferecerem ao paciente a possibilidade de retomar o seu processo de amadurecimento em primeira pessoa, podem finalmente devolver-lhe a condição de sujeito de sua própria história.

Isso posto, passemos às considerações sobre a temporalidade saudável descrita por Loparic. O que elas permitem concluir é que, na saúde psicossomática, o self expandese por todos os tempos de tal forma que, como diz Winnicott: "as pessoas [...] têm todas as idades ou nenhuma". Dessa maneira, (cada um de nós é, ao mesmo tempo, a criança traquinas que já foi no passado, o adolescente transgressor que brigava com os pais, bem como o velho sábio no qual, um dia, se tornará: personagens estas incluídas no adulto que se é hoje. Somos unos e múltiplos, simultaneamente. Estamos no aqui e no lá, em todo e qualquer lugar no qual pudermos nos projetar, fantasia e realidade caminhando juntas, de mãos dadas, mas sem se misturarem uma com a outra.

Essa constitui, talvez, a maior característica que distingue o homem dos outros animais: sua capacidade de transcendência temporal, de viver no presente e ser, ao 
mesmo tempo, capaz de se projetar no passado e no futuro, habitando todos os tempos. Como reles ser mortal, sem eternidade.

\section{Referências bibliográficas}

Little, M. (1990). Psychotic anxieties and containment - A personal record of an analysis with Winnicott, Northvale, New York, London: Jason Aronson Inc.

Loparic, Z. (2014). Temporalidade e regressão. Winnicott e-Prints, vol. 9, n. 2, pdf. http://revistas.dwwe.com.br/index.php/We-Prints/article/view/57

Naffah Neto, A. (2007). A problemática do falso self em pacientes de tipo borderline: revisitando Winnicott. In A. Naffah Neto Veredas Psicanalíticas: à sombra de Winnicott. Saarbrucken: Novas Edições Acadêmicas, pp. 143-169, 2017.

Naffah Neto, A. (2010). Falso self e patologia borderline no pensamento de Winnicott: antecedentes históricos e desenvolvimentos subsequentes. In: A. Naffah Neto. Veredas Psicanalíticas: à sombra de Winnicott. Saarbrucken: Novas Edições Acadêmicas, p. 170-192, 2017.

Torrinha, F. (s/d). Dicionário Latino Português, $5^{\mathrm{a}}$ edição, Porto: Gráficos Reunidos Ltda.

Torrinha, F. (1960a). Aggression, guilt and reparation. In D. W. Winnicott. Home is where we start from, London: Penguin, 1990, p. 80-89.

Torrinha, F. (1960b). Ego distortion in terms of true and false self. In: Winnicott, D.W. The maturational process and the facilitating environment, London: Karnac, 1990, p.140-152.

Torrinha, F. (1965). The Maturational Processes and the Facilitating Environment. London: Hogarth Press. Tradução brasileira: $O$ ambiente e os processos de maturação. Porto Alegre: Artes Médicas, 1983.

Torrinha, F. (1968). The use of an object and relating through identifications. In: Winnicott, D.W. Playing and Reality, London and New York: Routledge, 1991, p. 8694.

Torrinha, F. (1971). Transitional objects and transitional phenomena. In: Winnicott, D.W. Playing and Reality, London and New York: Routledge, 1991, p. 1-25. 
Torrinha, F. (1986). Home is where we start from. London: Penguin. Tradução brasileira: Tudo começa em casa. São Paulo: Martins Fontes, 1989. 